\title{
Isolation of mucoid strains of Pseudomonas aeruginosa from non-cystic-fibrosis patients and characterisation of the structure of their secreted alginate
}

\author{
M. J. McAVOY, VALERIE NEWTON, A. PAULL*, J. MORGAN*, P. GACESA and \\ N. J. RUSSELL
}

Department of Biochemistry, University of Wales College of Cardiff, PO Box 903, Cardiff CF1 $1 S T$ and *Department of Medical Microbiology, University of Wales College of Medicine, Heath Park, Cardiff CF4 4XW

\begin{abstract}
Summary. When the incubation period of primary isolation plates was extended to $48 \mathrm{~h}$, mucoid strains of Pseudomonas aeruginosa were found in specimens from various infected sites in patients who did not have cystic fibrosis. The 17 mucoid isolates were characterised in terms of mucoid type, pyocin type, and their sensitivity or resistance to seven $\beta$-lactam and two aminoglycoside antibiotics. The carbohydrate, uronic acid (alginate) and protein content of the water-soluble extracellular material of 15 strains was determined. This material was fractionated by ion-exchange chromatography, and the presence of alginate confirmed by the chemical assay of uronic acids and their quantitation by gas-liquid chromatography. Uronic acids were absent from a nonmucoid revertant of one strain. The strains produced alginate with a high content of mannuronic acid and substituted with $\mathrm{O}$-acetyl groups. By proton nuclear magnetic resonance $\left({ }^{1} \mathrm{H}\right.$-nmr) analysis the alginate from three strains was shown to lack polyguluronate blocks in its structure. These properties are also found in the alginate of mucoid $P$. aeruginosa strains from patients with cystic fibrosis.
\end{abstract}

\section{Introduction}

Pseudomonas aeruginosa can produce the polysaccharide alginate as a large-volume, viscous gel around the cell (Carlson and Mathews, 1966; Linker and Jones, 1966). This mucoid phenotype is observed most frequently in strains isolated from sputum of cystic fibrosis (CF) patients. Most CF patients become colonised, probably by the nonmucoid form of $P$. aeruginosa which later becomes mucoid (Govan and Harris, 1986). It is not known what stimulates the bacteria to synthesise alginate (Russell and Gacesa, 1988). Assumptions have been made that some factor specific to the CF condition is responsible and that the presence of mucoid $P$. aeruginosa can be used as a diagnostic indicator of cystic fibrosis. These assumptions are probably invalid, because mucoid $P$. aeruginosa strains are isolated occasionally from patients without CF (Evans and Linker, 1973) but comprehensive studies of these strains have not been made. It has not been shown whether they also secrete alginate or another extracellular polysaccharide and, if alginate is produced, whether it has the same

Received 6 April 1988; revised version accepted 8 Aug. 1988. structure as that from mucoid isolates from $\mathrm{CF}$ patients. If there is a difference between mucoid strains from $\mathrm{CF}$ and non-CF patients, this might provide a valuable clue to the control of alginate synthesis which, like the pathway, is poorly understood (Russell and Gacesa, 1988).

We have previously purified alginate from mucoid isolates of $P$. aeruginosa from patients with $C F$, studied its composition and structure, and used proton nuclear magnetic resonance $\left({ }^{1} \mathrm{H}\right.$-nmr) to elucidate the arrangement in the polymer of the two uronic acid monomers, $\beta$-D-mannuronic acid and $\alpha$-L-guluronic acid (Sherbrock-Cox et al., 1984). We now report some of the properties of mucoid isolates of $P$. aeruginosa from patients without $\mathrm{CF}$ and show that the alginate produced by them has essentially the same structure as that from isolates from patients with CF.

\section{Materials and methods}

\section{Isolation and maintenance of bacteria}

Over a 16-month period (Oct. 1983-Feb. 1985), specimens from patients with neither symptoms nor 
medical history of cystic fibrosis were plated out on MacConkey Agar (Difco) and grown at $37^{\circ} \mathrm{C}$ for $48 \mathrm{~h}$. Overtly mucoid colonies thought to be pseudomonads were picked, purified on Pseudomonas Isolation Agar (PIA; Difco 0927-01) and maintained on deoxycholate citrate agar slopes at $4^{\circ} \mathrm{C}$. For longer term storage they were kept in skimmed milk $10 \% \mathrm{w} / \mathrm{v}$ at $-70^{\circ} \mathrm{C}$.

\section{Identification of bacteria}

Isolates were identified as $P$. aeruginosa by colonial morphology, a positive oxidase reaction (Kovacs, 1956), oxidative utilisation of glucose (Hugh and Leifson, 1953), growth in peptone water after incubation for $48 \mathrm{~h}$ at $37^{\circ} \mathrm{C}$ and $42^{\circ} \mathrm{C}$, and production of pigment on PIA (King et al., 1954). Some isolates were also identified with API 2ONE kits (API Laboratory Products Ltd, Basingstoke).

The isolates were also examined for their ability to grow on minimal medium in the presence or absence of leucine. This is the basis of a simple typing method to determine the characteristics of mucoid growth (Fyfe and Govan, 1980).

\section{Antibiotic sensitivity testing}

All strains were tested for their sensitivity to a variety of antibiotics. Diagnostic Sensitivity Test Agar (DST, Oxoid CM 261) plates were inoculated with a swab charged with bacteria from a suspension in peptone water $(2 \mathrm{ml})$ at a density giving rise to semi-confluent growth. Antibiotic-containing disks were then applied to the agar surface and the plates were incubated for $24 \mathrm{~h}$ at $37^{\circ} \mathrm{C}$. The disks contained gentamicin $10 \mu \mathrm{g}$, tobramycin $10 \mu \mathrm{g}$, amoxycillin $10 \mu \mathrm{g}$, carbenicillin $100 \mu \mathrm{g}$, mezlocillin $75 \mu \mathrm{g}$, azlocillin $75 \mu \mathrm{g}$, cephradine $30 \mu \mathrm{g}$, cefuroxime $30 \mu \mathrm{g}$ or ceftriaxone $30 \mu \mathrm{g}$. A known sensitive strain of $P$. aeruginosa (NCTC 10662) was tested in a similar manner. Isolates were classified as sensitive, intermediate or resistant to antibiotics by comparison with the control strain according to the criteria specified in the WHO Technical Report Series No. 210 (1966).

\section{Pyocin typing}

Both the active technique of Gillies and Govan (1966) and the liquid-culture method of Williams and Govan (1973) were used for the production and detection of pyocins. Indicator strains 1-8 and sub-typing indicator strains A-E (Govan, 1978), obtained from Dr T. Pitt, Division of Hospital Infection, Central Public Health Laboratory, Colindale, were used to prepare bacterial lawns for testing the activity of pyocins from the isolates. In addition, control strains of known pyocin type were also tested within each set of experiments. The isolates were classified according to the criteria of Govan (1978).

\section{Extraction and purification of polysaccharide}

For each isolate, the growth from three PIA plates incubated at $37^{\circ} \mathrm{C}$ for $72 \mathrm{~h}$ was removed with a glass rod and crude water-soluble polysaccharide was separated from the cells by centrifugation (Sherbrock-Cox et al., 1984).

Samples $(50 \mathrm{mg})$ of extract were fractionated on Dowex 1-X2 by step-wise elution with $\mathrm{NaCl}$ as described before (Sherbrock-Cox et al., 1984), desalted on a Biogel P-6DG column $(3.2 \times 36.0 \mathrm{~cm})$, dialysed and freeze-dried before analysis for protein, carbohydrate and uronic-acid content.

\section{Analytical methods}

Protein was measured by the method of Lowry et al. (1951) with bovine serum albumin as standard. Total carbohydrate was assayed with phenol-sulphuric acid reagent (Dubois et al., 1956) and uronic acids with carbazole-borate reagent (Knutson and Jeanes, 1968) with either D-mannurono 6,3-lactone or D-galacturonic acid as standard. The $\mathrm{O}$-acetyl content of the alginate samples was assayed by the method of Buscher et al. (1974) with $\alpha$-D-glucose penta-acetate as standard.

Proton nuclear magnetic resonance $\left({ }^{1} \mathrm{H}-\mathrm{Nmr}\right)$ spectroscopy. Samples $(5 \mathrm{mg})$ of freeze-dried alginate the viscosity of which had been reduced by minimal hydrolysis ( $30 \mathrm{~min}, 100^{\circ} \mathrm{C}, \mathrm{pH} \mathrm{2.9)}$ in $\mathrm{HCl}$ followed by neutralisation with $\mathrm{NaOH}$, were added to EDTA $(3 \mathrm{mg})$ and dissolved in $\mathrm{D}_{2} \mathrm{O}(0.5 \mathrm{ml})$ at $\mathrm{pD} 7$. Spectra were obtained at $90^{\circ} \mathrm{C}$ with a Bruker WM-360 nmr spectrometer operating in the Fourier transform mode. A $180^{\circ}-\tau-90^{\circ}$ pulse sequence $(\tau \sim 3 \mathrm{~s})$ with a recycle time of $5 \mathrm{~s}$ was used to eliminate the solvent peak (HDO). ${ }^{1} \mathrm{H}$-Chemical shifts were expressed in ppm downfield from the internal standard of sodium 4,4-dimethyl-4-silapentane sulphonate. The assignment of peaks was based on previous work (Grasdalen et al., 1979) and confirmed by the use of algal alginate block structures of known composition (Haug and Larsen, 1962).

Gas-liquid chromatography. Samples of polysaccharide were methanolysed and the resulting methyl glycosides analysed as the trimethylsilyl ether derivatives by a modification of the method of Clamp et al. (1967). Thus, for samples in which the amino-sugar content was low, smaller than recommended amounts of acetic anhydride were used in the re-N-acetylation step. These amounts were determined empirically as the maximum concentration which did not cause $\mathrm{O}$-acetylation, as judged by the appearance of mono- and di-acetylated derivatives of the internal standard D-mannitol. The trimethylsilyl ether derivatives were analysed on a Pye 104 gas-liquid chromatograph on a column of SE30 $3 \% \mathrm{w} / \mathrm{w}$ on Gas Chrom Q (Phase Separation Ltd, Queensferry, Clwyd), temperature programmed from 140 to $250^{\circ} \mathrm{C}$ at $2^{\circ} \mathrm{C} / \mathrm{min}$ with a $\mathrm{N}_{2}$ carrier gas flow rate of $80 \mathrm{ml} / \mathrm{min}$ and injector and detector temperatures of $255^{\circ} \mathrm{C}$. Methyl glycosides were identified on the basis of their retention times relative to the internal standard, D-mannitol, and by comparison with those of known standards. 


\section{Results}

\section{Isolation and characterisation of mucoid strains}

Seventeen mucoid strains of $P$. aeruginosa were isolated from a large number of routine specimens taken over a 16-month period from patients without cystic fibrosis. The strains came from various clinical sites (table I).

Mucoid strains grew more slowly than nonmucoid strains and other organisms on primary isolation plates and incubation had to be extended to $48 \mathrm{~h}$ to permit the recognition of the mucoid phenotype. Six strains produced mucoid growth on minimal medium in the absence of leucine (type 1) and five required the addition of leucine to give mucoid growth (type 2). The remaining six isolates did not grow on minimal media and were nontypable (table I).

As in previous studies, several mucoid strains were non-typable by the pyocin typing method of Gillies and Govan (1966). Nearly all, however, were typable when liquid pyocin preparations were used (see table I).

The results of antibiotic sensitivity tests are summarised in table II. Most strains showed multiple resistances; all were resistant to cephradine, all but four to cefuroxime and all but five to amoxycillin. Two strains (N9 and N10) showed

Table I. The source, mucoid type and pyocin type of 17 mucoid isolates of $P$. aeruginosa from patients without $\mathrm{CF}$

\begin{tabular}{clll} 
Strain designation & Source & $\begin{array}{c}\text { Mucoid } \\
\text { type* }\end{array}$ & $\begin{array}{c}\text { Pyocin } \\
\text { type } \dagger\end{array}$ \\
\hline N1 & Throat swab & NT & 5NT \\
N2 & Urine & NT & $3 \mathrm{e}$ \\
N3 & Sputum & 2 & $1 \mathrm{e}$ \\
N4 & Sputum & 1 & $1 \mathrm{e}$ \\
N5 & Urine & 1 & $3 \mathrm{e}$ \\
N6, N7 & Ear swab & NT & $3 \mathrm{~h}$ \\
N8 & Ear swab & NT & $3 \mathrm{NT}$ \\
N9 & Urine & 2 & NT \\
N10 & Urine & 1 & $3 \mathrm{e}$ \\
N11 & Endotracheal tube & 2 & $5 \mathrm{y}$ \\
N12 & Urine & 1 & $3 \mathrm{e}$ \\
N13 & Sputum & 1 & $1 \mathrm{e}$ \\
N14 & Sputum & 2 & NT \\
N15 & Sputum & NT & NT \\
N16 & Sputum & 1 & $1 \mathrm{~b}$ \\
N17 & Lung abscess & 2 & 1 NT \\
& & & \\
\hline
\end{tabular}

* Typed according to the system of Fyfe and Govan (1980).

+ Typed by the liquid-culture method for the production of pyocins (Williams and Govan, 1973). The number refers to the indicator strain and the letter to the sub-typing indicator strain. $\mathrm{NT}=$ non-typable. intermediate resistance to ceftriaxone and they were the only isolates that were resistant to carbenicillin and mezlocillin. Except for strain $\mathrm{N} 10$, all were sensitive to azlocillin, and all but strains N8 and N9 were sensitive to the aminoglycosides.

\section{Analysis of mucoid material}

All strains readily produced mucoid material when grown on PIA plates. Analysis of watersoluble extracts of the material invariably showed the presence of carbohydrate, uronic acid and smaller amounts of protein (table III). Although the proportions of these three constituents differed among isolates, for most, carbohydrate comprised at least $60 \%$ of the total material and protein less than $20 \%$ of the total material. There was considerable variation in the uronic acid content, e.g., from 18 to $77 \%$ of the total carbohydrate extracted from these isolates (table III). With two strains (N5 and N10), the crude material was insoluble after lyophilisation and, therefore, analysis was not possible.

Fractionation of the water-soluble mucoid material on Dowex 1-X2 $\left(\mathrm{Cl}^{-}\right.$form $)$showed that most of the uronic-acid-containing material was eluted with $0.6,0.8$ and $1.0 \mathrm{M} \mathrm{NaCl}$. Samples of algal alginate also eluted from the Dowex 1-X2 column with 0.6 and $0.8 \mathrm{M} \mathrm{NaCl}$. Both non-uronic-acidcontaining carbohydrate (i.e., total carbohydrate less uronic acid) and protein were eluted over a wide range of salt concentrations with the latter, in particular, being eluted at the lower salt concentrations (figure).

All fractions of each sample from ion-exchange chromatography were analysed qualitatively by GLC to determine their sugar composition. In all fractions containing sufficient material for analysis (i.e., 105 of 119 samples) glucose, galactose, mannose, xylose and rhamnose were detected. D-Mannuronate was produced by all isolates and was found principally in the fractions eluting at 0.6 , 0.8 and $1.0 \mathrm{M} \mathrm{NaCl}$. L-Guluronate was also found in these fractions from all isolates except strains $\mathrm{N} 2$ and $\mathrm{N} 9$, in which this sugar could not be detected. Whether the absence of L-guluronate in these two isolates is because of insufficient material for analysis or the production of alginate composed entirely of polymannuronate is unclear. A nonmucoid revertant of strain $\mathrm{N} 11$ also had all of the sugars present in the water-soluble extract of the mucoid strains, but neither of the two uronic acids was detected.

Whenever sufficient material for analysis was 
Table II. Antibiotic sensitivity profiles of mucoid isolates of $P$. aeruginosa from patients without CF

\begin{tabular}{|c|c|c|c|c|c|c|c|c|c|}
\hline \multirow{2}{*}{$\begin{array}{l}\text { Strain } \\
\text { designation }\end{array}$} & \multicolumn{9}{|c|}{ Disk antibiotic sensitivities } \\
\hline & MEZ & $\mathrm{CXM}$ & AZL & AML & $\mathrm{CE}$ & $\mathrm{CN}$ & TOB & PY & ROC \\
\hline N1 & $\mathrm{S}$ & $\mathbf{R}$ & $\mathrm{S}$ & $\mathbf{R}$ & $\mathbf{R}$ & S & $\mathrm{S}$ & $S$ & $\mathrm{~S}$ \\
\hline $\mathrm{N} 2$ & $\mathrm{~S}$ & $\mathrm{R}$ & $\mathrm{S}$ & $S$ & $\mathrm{R}$ & $S$ & $S$ & S & $\mathrm{S}$ \\
\hline N3 & $\mathrm{S}$ & $\mathrm{S}$ & $S$ & $S$ & $\mathbf{R}$ & $\mathrm{S}$ & $S$ & S & S \\
\hline N4 & $\mathrm{S}$ & $\mathrm{S}$ & $S$ & $\mathrm{~S}$ & $\mathrm{R}$ & $S$ & $S$ & $S$ & $\mathrm{~S}$ \\
\hline N5 & $\mathrm{S}$ & $\mathbf{R}$ & $\mathrm{S}$ & $\mathbf{R}$ & $\mathrm{R}$ & $S$ & $S$ & $S$ & $\mathbf{S}$ \\
\hline N6, N7 & $\mathrm{S}$ & $\mathrm{R}$ & $S$ & $\mathbf{R}$ & $\mathrm{R}$ & $\mathrm{S}$ & $\mathrm{S}$ & $S$ & $\mathrm{~S}$ \\
\hline N8 & $\mathrm{S}$ & $\mathrm{R}$ & $\mathrm{S}$ & $\mathbf{R}$ & $\mathbf{R}$ & $\mathrm{R}$ & I & $S$ & $S$ \\
\hline N9 & I & $\mathrm{R}$ & $\mathrm{S}$ & $\mathrm{R}$ & $\mathrm{R}$ & $\mathrm{R}$ & $\mathrm{R}$ & I & I \\
\hline N10 & $\mathrm{R}$ & $\mathrm{R}$ & I & $\mathrm{R}$ & $\mathbf{R}$ & $S$ & $\mathrm{~S}$ & $\mathrm{R}$ & I \\
\hline N11 & $\mathrm{S}$ & $\mathrm{R}$ & S & $\mathbf{R}$ & $\mathbf{R}$ & $S$ & $\mathrm{~S}$ & $\mathrm{~S}$ & $S$ \\
\hline N12 & $\mathrm{S}$ & $\mathrm{R}$ & $\mathrm{S}$ & $\mathrm{R}$ & $\mathrm{R}$ & $\mathrm{S}$ & $\mathrm{S}$ & $\mathrm{S}$ & $\mathrm{S}$ \\
\hline N13 & $\mathrm{S}$ & $\mathbf{R}$ & $\mathrm{S}$ & $\mathrm{R}$ & $\mathbf{R}$ & $S$ & $S$ & $\mathrm{~S}$ & S \\
\hline $\mathrm{N} 14$ & $S$ & I & $\mathrm{S}$ & I & $\mathrm{R}$ & $\mathrm{S}$ & $\mathrm{S}$ & $\mathrm{S}$ & S \\
\hline N15 & $\mathrm{S}$ & $\mathrm{S}$ & $\mathrm{S}$ & $S$ & $\mathbf{R}$ & $S$ & $S$ & S & S \\
\hline N16 & $\mathrm{S}$ & $\mathbf{R}$ & $\mathrm{S}$ & $\mathrm{R}$ & $\mathrm{R}$ & $\mathrm{S}$ & $\mathrm{S}$ & $\mathrm{S}$ & $\mathrm{S}$ \\
\hline N17 & $\mathrm{S}$ & $\mathrm{S}$ & $\mathrm{S}$ & $\mathrm{S}$ & $\mathbf{R}$ & $\mathrm{S}$ & $S$ & $\mathrm{~S}$ & $\mathrm{~S}$ \\
\hline
\end{tabular}

MEZ, mezlocillin; CXM, cefuroxime; AZL, azlocillin; AML, amoxycillin; CE, cephradine; CN, gentamicin; TOB, tobramycin; PY, carbenicillin; ROC, ceftriaxone; S, sensitive (zone of inhibition similar to or greater than control); I, intermediate (zone diameter 4-10 $\mathrm{mm}$ smaller than control); $\mathrm{R}$, resistant (zone diameter > $10 \mathrm{~mm}$ smaller than control).

available, a semi-quantitative estimate was made of the proportions of the uronic acids in the samples based on GLC analysis (table IV). All isolates produced alginate containing a much higher proportion of mannuronate than guluronate, with 7 of 9 samples having $>80 \%$ mannuronate. Seven samples were also analysed for the presence of $\mathrm{O}$ acetyl groups. These were found in all but in differing amounts (table IV). The alginate fractions isolated from three strains were analysed quantitatively by ${ }^{1} \mathrm{H}-\mathrm{nmr}$ to obtain information about the nearest neighbour frequency of mannuronate and guluronate residues within the polysaccharide (table V). There was good agreement between the fractional compositions obtained separately by ${ }^{1} \mathrm{H}-\mathrm{nmr}$ and GLC analyses of these samples (see tables IV and V). The proportions of the various doublet frequencies (i.e., nearest neighbour analysis) showed that the alginate contained both polymannuronate and poly-mannuronate/guluronate (i.e., mixed) blocks, but that there was a complete absence of poly-guluronate blocks (table V).

\section{Discussion}

We have found that mucoid strains of $P$. aeruginosa can be isolated from patients who do not have $\mathrm{CF}$, although the frequency of isolation is very much less than that with $\mathrm{CF}$ patients. Mucoid strains of $P$. aeruginosa can be isolated from the sputum samples of $c .50 \%$ of patients with CF. In a 16-month period we obtained 17 mucoid isolates from non-CF patients without resort to special screening or selection procedures other than extending the incubation period. Because the mucoid phenotype is often slowly expressed, if primary isolation plates are only incubated for the conventional period of 18-24 h, mucoid strains may not be recognised. We suspect, therefore, that mucoid $P$. aeruginosa strains occur more frequently than hitherto believed. We recommend that plates be incubated for $48 \mathrm{~h}$ whenever chronic $P$. aeruginosa infection is suspected, because the presence of mucoid strains has considerable bearing on the decision as to the best antibiotic or other form of therapy.

Like mucoid strains of $P$. aeruginosa from CF patients, the 17 mucoid isolates from patients without $\mathrm{CF}$ showed typical resistance to cephradine whilst some were sensitive to amoxycillin and cefuroxime. This contrasts with non-mucoid strains from patients with or without $\mathrm{CF}$ which are always resistant to these antibiotics. Only two strains showed multiple resistance to $\beta$-lactam antibiotics and one of them was also resistant to the aminoglycosides. The phenomenon of increased sensitiv- 
Table III. Composition of the extracellular material isolated from mucoid strains of $P$. aeruginosa from patients without $\mathrm{CF}$

\begin{tabular}{|c|c|c|c|c|}
\hline \multirow[b]{2}{*}{$\begin{array}{l}\text { Strain } \\
\text { designation }\end{array}$} & \multicolumn{3}{|c|}{$\begin{array}{l}\text { Percentage composition* } \\
\text { of extracellular material }\end{array}$} & \multirow{2}{*}{$\begin{array}{c}\text { uronic acid } \\
\text { as percentage } \\
\text { of carbo- } \\
\text { hydrate } \dagger\end{array}$} \\
\hline & protein & $\begin{array}{l}\text { carbo- } \\
\text { hydrate }\end{array}$ & $\begin{array}{l}\text { uronic } \\
\text { acid } \dagger\end{array}$ & \\
\hline $\mathrm{N} 1$ & 8 & 75 & 26 & 35 \\
\hline $\mathrm{N} 2$ & 25 & 49 & 13 & 26 \\
\hline N3 & 27 & 61 & 21 & 34 \\
\hline N4 & 24 & 84 & 22 & 26 \\
\hline N5 & N.D. & N.D. & N.D. & N.D. \\
\hline N6, N7 & 16 & 40 & 31 & 77 \\
\hline N8 & 14 & 89 & 42 & 47 \\
\hline N9 & 12 & 72 & 13 & 18 \\
\hline N10 & N.D. & N.D. & N.D. & N.D. \\
\hline Nil & 10 & 63 & 22 & 35 \\
\hline $\mathrm{N} 12$ & 15 & 59 & 15 & 25 \\
\hline $\mathrm{N} 13$ & 11 & 69 & 28 & 41 \\
\hline $\mathrm{N} 14$ & 9 & 84 & 21 & 25 \\
\hline $\mathrm{N} 15$ & 8 & 63 & 40 & 63 \\
\hline N16 & 15 & 69 & 18 & 26 \\
\hline N17 & 11 & 57 & 30 & 53 \\
\hline
\end{tabular}

* Values are expressed as percentages of the total weight on the basis of chemical assays of individual components and gravimetric determination of total weight. The presence of variable amounts of water in different samples probably accounts for the fact that the sum of the individual components is not always $100 \%$.

† Uronic acids give a positive reaction in both the total carbohydrate and the uronic-acid assays.

N.D. $=$ not determined.

Table IV. Fractional uronic acid content and extent of Oacetylation of the alginate in samples isolated from some mucoid strains of $P$. aeruginosa

Fractional content of residues

Strain mannuronate guluronate

Molar ratio of designation mannuronate guluronate acetate:uronate

\begin{tabular}{llll} 
N1 & 0.82 & 0.18 & 0.48 \\
N7 & 0.82 & 0.18 & N.D. \\
N8 & 0.83 & 0.17 & 0.26 \\
N11 & 0.62 & 0.38 & 0.08 \\
N12 & 0.78 & 0.22 & 0.23 \\
N14 & 0.88 & 0.12 & 0.60 \\
N15 & 0.90 & 0.10 & N.D. \\
N16 & 0.84 & 0.16 & 0.52 \\
N17 & 0.85 & 0.15 & 0.06 \\
\hline
\end{tabular}

N.D. = not determined.
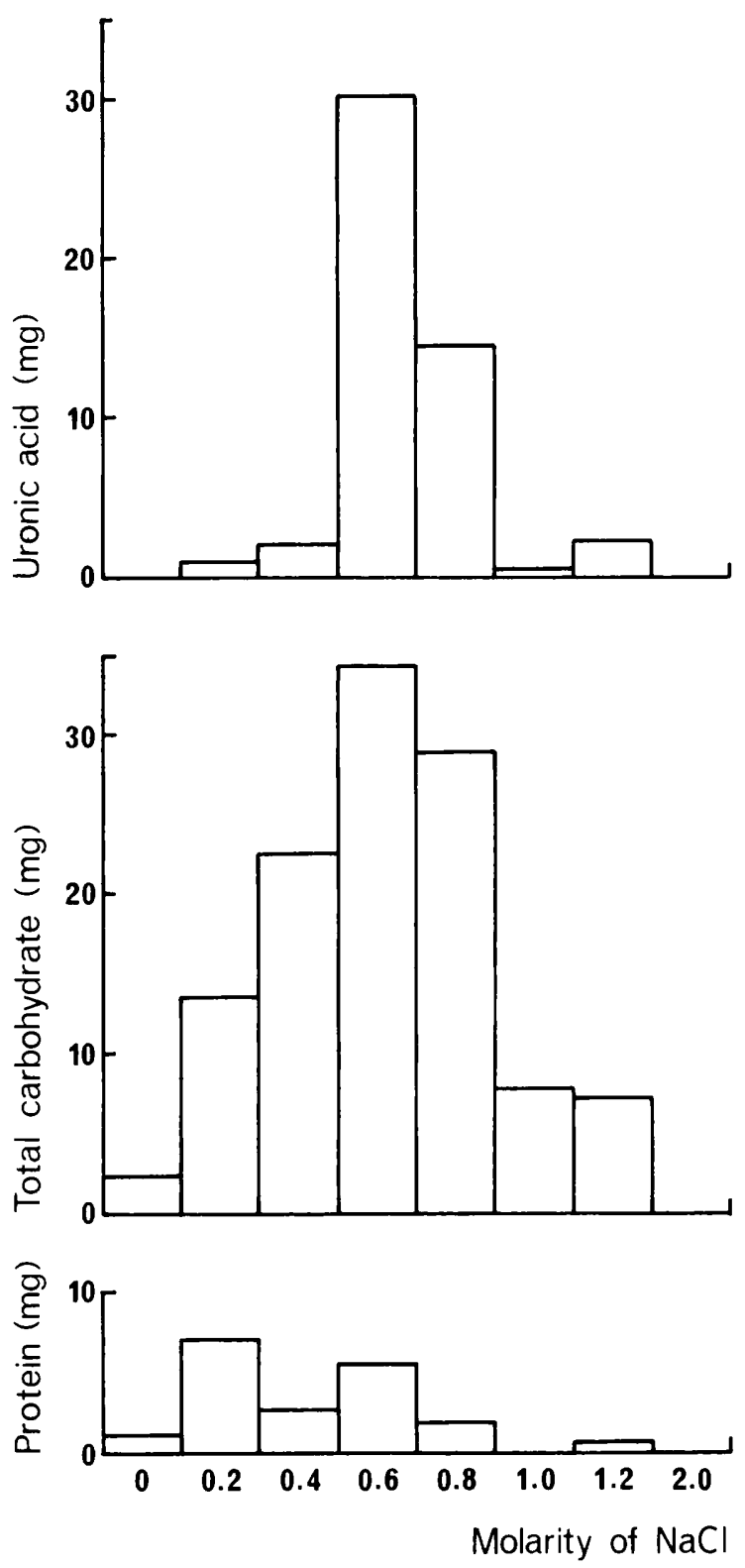

Figure. Ion-exchange chromatography elution profile of crude extracellular material isolated from $P$. aeruginosa strain $\mathrm{N} 1$. The sample $(436 \mathrm{mg}$ ) was fractionated on Dowex 1-X2 with stepwise elution with $\mathrm{NaCl}$ as described by Sherbrock-Cox et al. (1984). Fractions were analysed for uronic acid (top), total carbohydrate (centre) and protein (bottom).

ity to antibiotics (when measured in laboratory tests) of mucoid strains of $P$. aeruginosa from patients with CF compared with other non-mucoid strains has been termed "hypersensitivity" (Govan et al., 1983). In this paper we report the first demonstration of "hypersensitivity" in strains of $P$. aeruginosa from patients without CF. 
Table V. ${ }^{1} \mathrm{H}$-nmr analysis of the alginate from three mucoid strains of $P$. aeruginosa

\begin{tabular}{|c|c|c|c|c|c|c|}
\hline \multirow{2}{*}{$\begin{array}{l}\text { Strain } \\
\text { designa- } \\
\text { tion }\end{array}$} & \multicolumn{6}{|c|}{ Fractional composition } \\
\hline & guluronate & mannuronate & $F_{\mathrm{GG}}$ & $F_{M M}$ & $\mathrm{~F}_{\mathrm{MG}}$ & $\mathrm{F}_{\mathrm{GM}}$ \\
\hline $\mathrm{Nl}$ & 0.23 & 0.77 & 0 & 0.54 & 0.23 & 0.23 \\
\hline N11 & $0 \cdot 27$ & 0.73 & 0 & 0.45 & $0 \cdot 28$ & $0 \cdot 28$ \\
\hline $\mathrm{N} 12$ & $0 \cdot 30$ & $0 \cdot 70$ & 0 & 0.41 & $0 \cdot 29$ & 0.29 \\
\hline
\end{tabular}

$\mathrm{GG}=$ guluronate adjacent to guluronate.

$\mathrm{MM}=$ mannuronate adjacent to mannuronate

$\mathrm{MG}=$ mannuronate adjacent to guluronate.

$\mathrm{GM}=$ guluronate adjacent to mannuronate.

Although it had been shown previously (Evans and Linker, 1973) that mucoid isolates from patients without CF occurred rarely and could produce alginate, there has been no comprehensive study of the extracellular material from these organisms. We have demonstrated that, as with mucoid strains from patients with $\mathrm{CF}$, this material contained a mixture of alginate and other polysaccharides, including lipopolysaccharide (LPS), and a smaller amount of protein. On fractionation by ionexchange chromatography, the fractions containing most alginate eluted in 0.6 and $0.8 \mathrm{M} \mathrm{NaCl}$, as did those containing alginate from isolates from patients with CF (see, however, Sherbrock-Cox et al., 1984). The identity of alginate was confirmed both by chemical analysis of uronic acids and by quantitation of their relative amounts by GLC analysis. The latter technique also showed that the extracellular material contained LPS and neutral sugars. Since the latter are known to be components of LPS in P. aeruginosa (Chester et al., 1972) and were present in the water-soluble extract of the non-mucoid revertant of strain N11, it would appear that both neutral sugars and LPS are

\section{REFERENCES}

Buscher H P, Casals-Stenzel J, Schauer R 1974 New sialic acids. Identification of $\mathrm{N}$-glycoloyl-O-acetylneuraminic acids and $\mathrm{N}$-acetyl-O-glycoloylneuraminic acids by improved methods for detection of $\mathrm{N}$-acyl and $\mathrm{O}$-acyl groups and by gasliquid chromatography. European Journal of Biochemistry 50: $71-82$.

Carlson D M, Matthews L W 1966 Polyuronic acids produced by Pseudomonas aeruginosa. Biochemistry $5: 2817-2822$.

Chester I R, Gray G W, Wilkinson S G 1972 Further studies of the chemical composition of the lipopolysaccharide of Pseudomonas aeruginosa. Biochemical Journal 126: 395-407.

Clamp J R, Dawson G, Hough L 1967 The simultaneous estimation of 6-deoxy-L-galactose (L-fucose), D-mannose, D-galactose, 2-acetamido-2-deoxy-D-glucose (N-acetyl-D- contaminants rather than components of the extracellular material and that they were removed from the bacterial outer membrane during isolation of the mucoid material.

It was of particular interest to analyse the structure of the alginate to determine whether any differences existed between that of strains from patients with or without $\mathrm{CF}$, because this might give clues as to the regulation of biosynthesis of this polymer. The isolates from patients without $C F$ all produced alginate that was rich in mannuronate, although the proportion of alginate in the extracellular material varied quite widely among isolates. Moreover, ${ }^{1} \mathrm{H}$-nmr analysis demonstrated that the alginate in all three strains investigated comprised blocks of poly-mannuronate and poly-mannuronate/guluronate whilst blocks of poly-guluronate were completely absent. The same block structure was found previously for the alginate from isolates from patients with CF (Sherbrock-Cox et al., 1984). Furthermore, all of the samples examined contained $\mathrm{O}$-acetyl groups and although the molar ratio of acetate: uronate varied from sample to sample, the values obtained were similar to those reported for isolates from patients with CF (Evans and Linker, 1973; Sherbrock-Cox et al., 1984).

In conclusion, mucoid strains of $P$. aeruginosa from patients without $C F$ may be more common than hitherto realised. This is because the development of the mucoid phenotype requires longer than the usual incubation times used in routine bacteriology laboratories. The extracellular material produced by these strains is composed mainly of alginate and has a similar composition to that produced by isolates of $P$. aeruginosa from patients with $\mathrm{CF}$.

We are grateful to the Welsh Scheme for the Development of Health and Social Research for financial support.

glucosamine) and $\mathrm{N}$-acetylneuraminic acid (sialic acid) in glycopeptides and glycoproteins. Biochimica et Biophysica Acta 148: 342-349.

Dubois M, Gilles K A, Hamilton J K, Rebers P A, Smith F 1956 Colorimetric method for determination of sugars and related substances. Analytical Chemistry 28: 350-356.

Evans L R, Linker A 1973 Production and characterization of the slime polysaccharide of Pseudomonas aeruginosa. Journal of Bacteriology 116: 915-924.

Fyfe J A M, Govan J R W 1980 Alginate synthesis in mucoid Pseudomonas aeruginosa: a chromosomal locus involved in control. Journal of General Microbiology 119 : 443-450.

Gillies R R, Govan J R W 1966 Typing of Pseudomonas pyocyanea by pyocine production. Journal of Pathology and Bacteriology 91 : 339-345.

Govan J R W 1978 Pyocin typing of Pseudomonas aeruginosa. In 
Bergen T, Norris J R (eds) Methods in microbiology, vol 10. Academic Press, London, pp 61-91.

Govan J R W, Fyfe J A M, Baker N R 1983 Heterogeneity and reduction in pulmonary clearance of mucoid Pseudomonas aeruginosa. Reviews of Infectious Diseases 5 Suppl 5: S874S879.

Govan J R W, Harris G S 1986 Pseudomonas aeruginosa and cystic fibrosis: unusual bacterial adaptation and pathogenesis. Microbiological Sciences 3: 302-308.

Grasdalen H, Larsen B, Smidsrod O 1979 A p.m.r. study of the composition and sequence of uronate residues in alginates. Carbohydrate Research 68 : 23-31.

Haug A, Larsen B 1962 Quantitative determination of the uronic acid composition of alginates. Acta Chimica Scandinavica 16: $1908-1918$.

Hugh R, Leifson E 1953 The taxonomic significance of fermentation versus oxidative metabolism of carbohydrates by various gram-negative bacteria. Journal of Bacteriology 66: $24-26$.

King E O, Ward M K, Raney D E 1954 Two simple media for the demonstration of pyocyanin and fluorescin. Journal of Laboratory and Clinical Medicine 44: 301-307.

Knutson C A, Jeanes A 1968 Determination of the composition of uronic acid mixtures. Analytical Biochemistry 24: 482 490.
Kovacs N 1956 Identification of Pseudomonas pyocyanea by the oxidase reaction. Nature 178: 703 .

Linker A, Jones R S 1966 A new polysaccharide resembling alginic acid isolated from pseudomonads. Journal of Biological Chemistry 241 : 3845-3851.

Lowry O H, Rosebrough N J, Farr A L, Randall R J 1951 Protein measurement with the folin phenol reagent. Journal of Biological Chemistry 193: 265-275.

Russell N J, Gacesa P 1988 Chemistry and biology of the alginate of mucoid strains of Pseudomonas aeruginosa in cystic fibrosis. Molecular Aspects of Medicine 10: 1-91.

Sherbrock-Cox V, Russell N J, Gacesa P 1984 The purification and chemical characterisation of the alginate present in the extracellular material produced by mucoid strains of Pseudomonas aeruginosa. Carbohydrate Research 135: 147154.

Williams R J, Govan J R W 1973 Pyocine typing of mucoid strains of Pseudomonas aeruginosa isolated from children with cystic fibrosis. Journal of Medical Microbiology 6: 409412.

World Health Organization Technical Report Series No. 210 1961. Standardization of methods for conducting microbial sensitivity tests. 